\title{
ANALISIS STRUKTUR BATUAN DENGAN METODA INVERSI SMOOTHNESS-CONSTRAINED LEAST-SQUARES DATA GEOLISTRIK KONFIGURASI SCHLUMBERGER DI UNIVERSITAS NEGERI PADANG KAMPUS AIR TAWAR
}

\author{
Akmam, Nofi Yendri Sudiar \\ Juruan Fisika FMIPA UNP Padang. Kampus Airtawar Padang Sumbar. \\ akmamdatuk@gmail.com
}

\begin{abstract}
Abstrak. Gempa Bumi 30 September 2009 diperkirakan telah merusak struktur batuan di UNP Padang Kampus Airtawar. Struktur batuan di bawah permukaan dapat mempengaruhi bangunan yang ada di atasnya. Berdasarkan hal di atas, telah dilakukan penelitian yang bertujuan untuk mengetahui kondisi struktur batuan berdasarkan nilai tahanan jenis batuan di UNP Airtawar. Penelitian eksplorasi ini menggunakan metoda Geolistrik tahanan jenis konfigurasi Wenner-Schlumberger. Data yang dikumpulkan menggunakan GF Instruments ARES diolah mengunakan metoda inversi smoothness-constrained least-squares. Eksplorasi dilakukan dalam empat lintasan. Hasil analisa data menunjukkan bahwa struktur yang terdapat di UNP Padang adalah Sandstone, silt dan Alluvium, Andesite dan airtanah yang terkontaminasi oleh air laut. Pada kawasan Kampus UNP Bagian Barat terlihat telah terjadi penyusupan Sandstone ke lapisan silt sejauh 36 meter sebaliknya pada Kampus UNP sebelah Timur struktur batuannya masih selaras.
\end{abstract}

Key Words: Batuan, Tahanan Jenis, smoothness-constrained least-squares,

\section{PENDAHULUAN}

Gempa bumi yang terjadi 30 September 2009 mengakibatkan terganggunya struktur batuan dan bangunan di atasnya. Agar bangunan dan fasilitas umum, seperti gedung perkuliahan, perkantoran aman dari goncangan gempa yang akan datang dibutuhkan pengetahuan tentang kondisi struktur batuan dimana bangunan tersebut didirikan. Informasi tentang kondisi struktur batuan di bawah permukaan bumi dibutuhkan dalam perencanaan pondasi pembangunan.

Informasi mengenai kondisi bawah permukaan bumi yang perlu diketahui kedalaman batuan dasar dan jenis batuan. Informasi mengenai kondisi batuan bawah permukaan bumi tempat bangunan akan didirikan berguna untuk meminimalisasi resiko terhadap kerusakan akibat terjadinya gempa maupun penurunan tanah. Salah satu metoda yang dapat digunakan untuk memperkirakan batuan penyusun lapisan batuan bawah permukaan bumi adalah metoda Geolistrik tahanan jenis. Nilai tahanan jenis batuan dapat diketahui dengan menggunakan metoda Geolistrik tahanan jenis. Metoda Geolistrik dengan berbagai konfigurasi elektroda banyak digunakan dalam teknik geofisika, khususnya investigasi airtanah dan struktur dekat permukaan[5]. Batuan dasar (basement rock) merupakan batuan metamorf ataupun batuan beku (tanpa memperdulikan umurnya) yang secara tidak selaras terlapisi di atasnya suatu formasi batuan sedimen [1],[2]. Batuan dasar umumnya memiliki karateristik keras dan brittle dengan porositas matrik dan permeabilitas yang rendah [1].

Tahanan jenis batuan di bawah permukaan bumi dipelajari dengan menginjeksikan arus listrik ke dalam bumi melalui dua buah elektroda arus. Arus listrik yang mengalir pada lapisan batuan tergantung pada jenis batuan yang dilaluinya. Beda potensial yang dihasilkan 
diukur melalui dua buah elektroda lainnya [3],[4].

Pencitraan tahanan jenis secara umum digunakan untuk berbagai survei teknik sipil, lingkungan hidrologi, pertanian dan mineral [6]. Metoda Geolisrik dengan konfigurasi Wenner- Schlumberger menggunakan empat buah elektroda dengan dua elektroda arus dan dua elektroda potensial yang disusun dalam satu garis lurus [7], seperti yang terlihat pada Gambar 1.

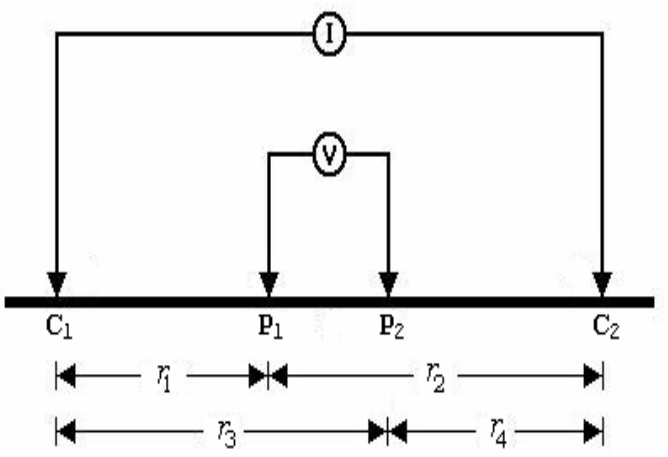

Gambar 1. Konfigurasi Wenner-Schlumberger

Tahanan jenis yang terukur pada metoda geolistrik bukanlah tahanan jenis yang sesungguhnya, melainkan tahanan jenis semu [9], dimana harganya dihitung dengan persamaan $\rho_{a}=K \frac{\Delta V}{I}$, dengan $\rho_{a}$ adalah tahanan jenis semu (apparent resistivity) yang bergantung pada jarak elekroda (faktor geometri, K). Nilai $K$ konfigurasi Schulumberger, sebagai berikut:

$$
K=\pi \frac{L^{2}}{4 l}\left[1-\frac{l^{2}}{L^{2}}\right]
$$

Berdasarkan nilai $K$ yang diperoleh maka dapat dihitung nilai tahanan jenis semu (apparent resistivity) untuk konfigurasi Schlumberger :

$$
\rho_{a}=\pi \frac{L^{2}}{4 l}\left[1-\frac{l^{2}}{L^{2}}\right] \frac{\Delta V}{I}
$$

dimana, $\rho_{a}$ adalah tahanan jenis semu, $L$ adalah jarak elektroda arus, $l$ adalah jarak elektroda potensial, $\Delta V$ adalah beda potensial, $I$ adalah kuat arus.

Tahanan jenis yang terukur sewaktu pengukuran adalah tahanan semu dimana untuk mengestimasi distribusi tahanan jenis sesungguhnya dari tahanan jenis semu terhadap kedalaman dapat dilakukan dengan metoda inversi. Metoda inversi umumnya tidak menghasil solusi yang unik, tetapi hasil inversi sangat terpengaruh harga estimasi awal [10],[11],[12] , dimana perubahan sedikit dalam data menyebabkan merubahan besar pada model [3],[19]. Salah satu penyebab tidak untuk solusi inversi adalah tidak linearnya hubungan tahanan semu dengan parameter model (tahanan jenis sesungguhnya dan ketebalan lapisan [3].

Optimasi inversi dilukakan dengan meminimalisasi perbedaan antara nilai resistivitas semu yang dihitung dan diukur dengan menyesuaikan resistivitas model blok. Acuan yang secara umum digunakan adalah harga kesalahan akar rata-rata kuadrat (root mean-square), namun model dengan error RMS rendah kadang-kadang mendapatkan variasi nilai-nilai resistivitas yang besar dan tidak realistis mengacu kepada perspektif geologi. Hal di atas dapat ditanggulangi dengan mengunakan dekomposisi nilai singular [3],[13]. Kelemahan pendekatan di atas, pada kondisi tertentu (untuk lapisan tipis) proses iterasi dapat mencapai divergen.

Pendekatan yang digunakan untuk mengatasi hal di atas, untuk pengolahan data metoda geolistrik adalah dengan pendekatan Smoothness-Constrained LeastSquares [4], [14], [15], [18]

$$
\left(J^{T} T+\mu F\right) d=J^{T} g-\mu F r,
$$


dimana $F=f_{x} f_{x}^{T}+f_{z} f_{z}^{T}$ dengan $\quad \mathrm{f}_{\mathrm{x}}=$ filter flatness horizontal, $\mathrm{f}_{\mathrm{x}}=$ filter flatness vertikal, $\mathrm{J}=$ matriks dari turunan parsial, $\mu$ $=$ faktor damping, $\mathbf{d}=$ vektor perturbasi dari model dan $\mathbf{g}=$ vektor discrepancy dan $\mathbf{r}=$ vektor yang logaritma dari nilai [4]

Salah satu keuntungan metoda ini adalah faktor damping dan filter dapat disesuaikan bermacam-macam tipe data. Nilai estimasi awal dapat ditambahkan kepada parameter model dalam proses inversi dengan faktor koreksi sebesar

$$
\Delta m=L_{\text {diag }}\left\{\frac{\alpha_{j}}{\alpha_{j}^{2}+\beta^{2}}\right\} U^{T} \Delta d
$$

dimana untuk $n$ banyak data dan $m$ banyak parameter $\mathrm{U}(\mathrm{n} \times \mathrm{m})$ dan $\mathrm{L}(\mathrm{m} \times \mathrm{m})$ matrik orthogonal yang mengandung masing spasi data dan vektor eigen parameter spasi data, serta $\Delta d$ data pada setiap vector yang berbeda.

Secara umum, estimasi awal diharapkan membantu pemodelan inversi sehingga diperoleh hasil yang dianggap paling tepat dengan kondisi bawah permukaan. Cara yang paling efektif untuk menginversi data adalah dengan melakukan constraint [15]. Hasil dengan melakukan constraint lebih akurat dibanding hasil yang tidak melakukan constraint. Proses constraint dilakukan secara otomatis. Pemilihan metoda Smoothness-Constrained LeastSquares inversion akan meminimalkan perbedaan antara data lapangan dan model yang diprediksi melalui pemodelan 2D.

Interprestasi data perhitungan tahanan jenis sesungguhnya koreksi dengan data kedalaman sumur air tanah terdapat di sekitar daerah penelitian (Universitas Negeri Padang Kampus Air Tawar). Sumur air tanah terdalam adalah 12,5 meter dan terdangkal adalah 8,3 meter terdapat pada lokasi Jl. Belibis Airtawar Padang.

\section{METODE PENELITIAN}

Penelitian deskriptif dilaksanakan di Universitas Negeri Padang Kampus Air Tawar. Parameter yang diukur adalah kuat arus injeksi $(I)$, tegangan terjadi $(V)$, dan jarak elektroda dan parameter yang terhitung adalah nilai tahanan jenis semu $\left(\rho_{a}\right)$. Alat pengumpul data adalah GF Instrument ARES. Pengukuran dilaksanakan pada 4 lintasan. Interpretasi data menggunakan metoda inversi Smoothness-Constrained Least-Squares melalui persamaan (3) dengan bantuan software Res2Dinv dari Goetoma Software, dengan pehitungan nilai damping dibuat secara menual menggunakan persamaan (4). Estimasi struktur batuan digunakan data kedalaman sumur bor milik penduduk yang ada disekitar lokasi penelitian serta merujuk kepada peta Geologi daerah survey.

\section{HASIL DAN PEMBAHASAN}

\section{Lintasan 1 (Labor Fisika-Kimia)}

Lintasan 1 berada pada Laboratorium Fisika dan Kimia FMIPA UNP Padang yang terbentang dari $00^{0} 53^{\prime} 51,7^{\prime}$ 'LS dan $100^{\circ} 21^{\prime} 0,6$ 'BT ke $00^{0} 53$ ' 53,5 'LS dan $100^{\circ} 21$ '0,1'BT, titik sounding di $00^{0} 53$ '52, 1 'LS dan $100^{0} 21^{\prime} 0,8^{\prime \prime}$ 'BT.

Gambar 2 memperlihatan rentangan nilai tahanan jenis daerah survey adalah antara 0.116 - $2803 \Omega \mathrm{m}$ dengan kedalaman hingga 56,9 meter, pada iterasi ke-3 dengan absolut error $2.1 \%$. Pada lintasan ini diestimasi terdapat lapisan Sandstone, silt dan Alluvium, Andesite dan airtanah yang terkontaminasi oleh air laut. Pada lintasan ini terlihat terjadinya penyusupan Sandstone ke lapisan silt dan adanya silt yang mendesak permukaan. Hal ini yang diperkirakan penyebab terangkatnya lantai laboratorium Fisika FMIPA UNP Padang, saat terjadinya Gempabumi tanggal 30 September 2009. 


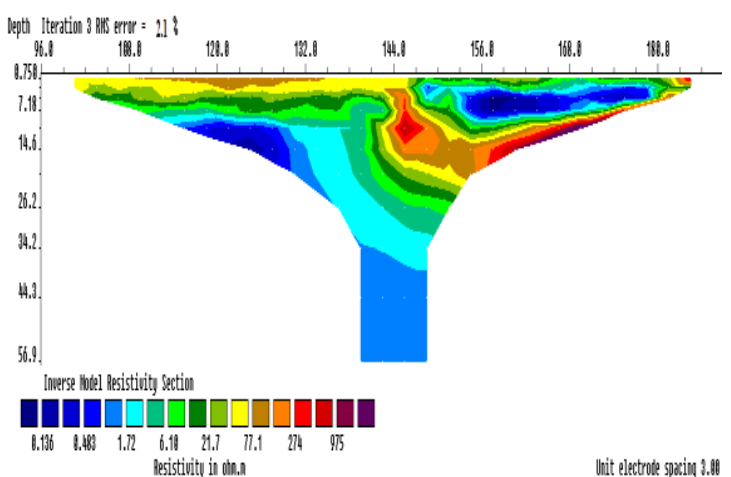

Gambar 2. Penampang Model 2D Lintasan Labor Fisika-Kimia.

\section{Lintasan 2 (Perpustakaan - FIK)}

Lintasan 2 berada antara lapangan sepakbola FIK dengan perpustakaan UNP terbentang dari $00^{0} 53^{\prime} 55,2^{\prime \prime} \mathrm{LS}$ dan $100^{0} 20^{\prime} 50,6^{\prime \prime} \mathrm{BT}$ ke $00^{0} 53^{\prime} 42,7^{\prime \prime} \mathrm{LS}$ dan $100^{\circ} 20^{\prime} 50,5$ 'BT, titik sounding pada $00^{0} 53^{\prime} 48,9$ 'LS dan $100^{0} 20$ '50,6”BT.

Gambar 3 memperlihatkan nilai rentangan tahanan jenis lintasan 2 yaitu $0,8876 \Omega \mathrm{m}$ sampai dengan $2435 \Omega \mathrm{m}$ dengan absolute error $6.6 \%$ pada iterasi ke-3, diestimasi pada lintasan ini terdapat Sandstone, silt dan Alluvium, Andesite dan airtanah terdapat pada kedalaman (12.5 36.9) meter. Pada lintasan ini juga memperlihatkan adanya penyusupan Sandstone ke lapisan silt sejauh 36 meter dan adanya silt yang mendesak permukaan. Hal ini yang diperkirakan penyebab rusaknya Lapangan Tenis dan Perpustakaan UNP Padang, saat terjadinya Gempabumi tanggal 30 September 2009.

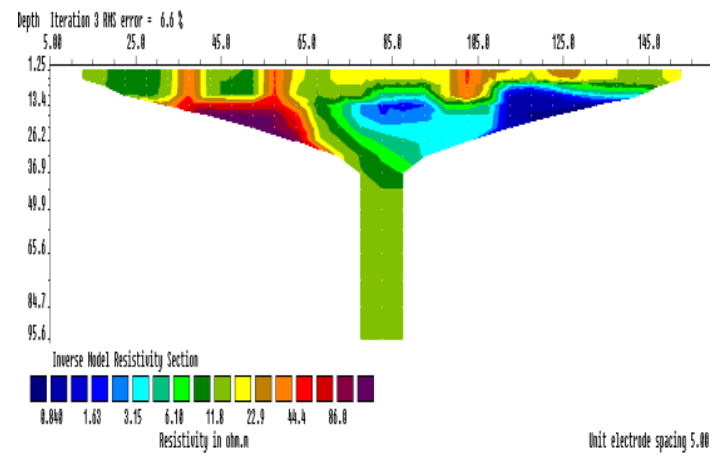

Gambar 3. Penampang Model 2D Lapangan Sepakbola-Perpustakaan UNP.

\section{Lintasan 3 (Balai Bahasa-Masjid UNP)}

Lintasan 3 terbentang pada $00^{0} 53^{\prime} 53,0$ '"LS dan $100^{0} 21^{\prime} 03,01$ 'BT ke $00^{0} 53^{\prime} 58,0$ 'LS dan $100^{0} 21^{\prime} 01,6$ 'BT, titik sounding pada $00^{0} 53^{\prime} 55,7$ ' LS dan $100^{0} 21$ '02,3”BT.

Gambar 4 memperlihatkan profil bawah permukaan sepanjang Labor Bahasa Inggris-Masjid Al-Azhar dengan distribusi nilai tahanan jenis 1.433 sampai $1568 \Omega \mathrm{m}$ dengan absolute error $8.8 \%$ pada iterasi ke-3. Gambar 4 memperlihatkan bahwa struktur batuan yang terdiri dari Alluvium dan Sandstones, clay dan silt masih selaras. Groundwater diperkirakan ditemukan pada kedalaman 16,6 meter. Struktur batuan pada lintasan 3 ini diperkirakan tidak mengalami deformasi pada gempabumi 30 September 2012. Indikasi lain adalah bangunan yang ada pada lintasan ini tidak mengalami rusak berat

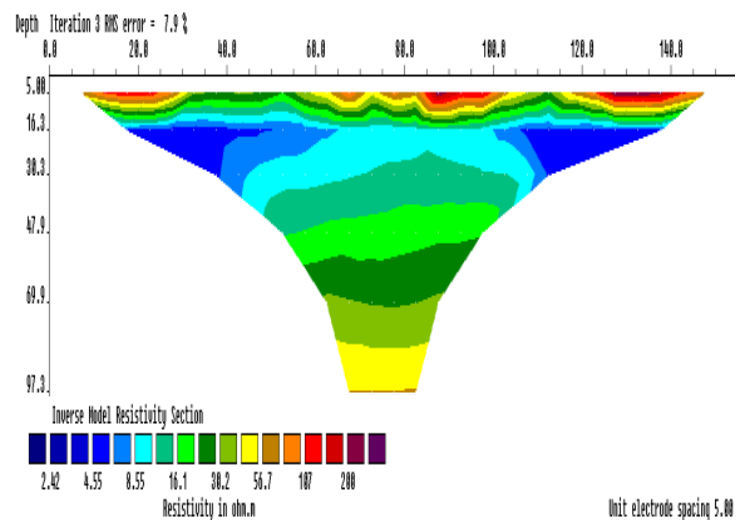

Gambar 4. Penampang Model 2D Lintasan Balai Bahasa Inggris-Masjid AlAzhar

\section{Lintasan 4 (FIS-FIP)}

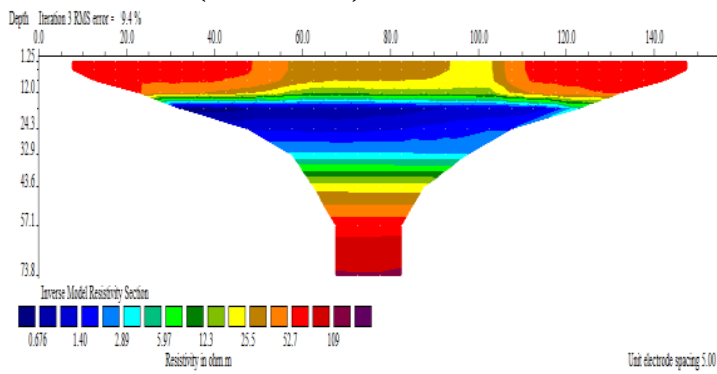

Gambar 5. Penampang Model 2D Lintasan FIS -FIP UNP 
Lintasan 4 terbentang pada $00^{\circ} 53^{\prime} 41,6$ "LS dan $100^{\circ} 20^{\prime} 59,2$ 'BT ke $00^{0} 53^{\prime} 46,5$ 'LS dan $100^{\circ} 21^{\prime} 00,4$ 'BT, titik sounding pada $00^{0} 53^{\prime} 44,0$ 'LS dan $100^{0} 20^{\prime} 79,8^{\prime \prime B T}$.

Gambar 5 memperlihatkan profil bawah permukaan sepanjang. Lintasan 4 dengan distribusi nilai tahanan jenis antara 1.684 $\Omega \mathrm{m}$ sampai dengan $986.45 \Omega \mathrm{m}$ dengan absolut error $8,7 \%$ pada iterasi ke-3. Gambar 5 memperlihatkan bahwa struktur batuan yang terdiri dari Alluvium dan Sandstones, clay dan silt masih selaras. Groundwater diperkirakan ditemukan pada kedalaman 16,6 meter. Struktur batuan pada lintasan 4 ini diperkirakan tidak mengalami deformasi pada gempabumi 30 September 2012. Berdasarkan interpretasi data.

Groundwater diperkirakan pada lintasan 4 ditemukan pada kedalaman $12.43 \mathrm{~m}$, berdasarkan hasil observasi yang dilakukan peneliti didapat bahwa kedalaman sumur bor yang dekat dengan lintasan ini adalah 10.5 meter, yaitu sumur yang terdapat di Belakang FIS dekat FE, hal ini membuktikan bahwa memang ditemukan Groundwater pada kedalaman 12,43 meter letak sumur bor kemungkinan memang berada di tengah Groundwater ditemukan untuk mendapatkan air yang bersih.

\section{KESIMPULAN}

Rentangan nilai tahanan jenis batuan penyusun struktur di bawah permukaan di Kampus UNP Airtawar Padang adalah antara 0.116 - $2803 \Omega \mathrm{m}$ dengan kedalaman hingga 56,9 meter, Bantuan penyusun struktur ini diestimasi terdiri dari Sandstone, silt dan Alluvium, Andesite dan airtanah yang terkontaminasi oleh air laut. Pada kawasan Kampus UNP bagian Barat terlihat telah terjadi penyusupan Sandstone ke lapisan silt sejauh 36 meter disekitar lapangan tenis UNP dan 30 meter di laboratorium Fisika-Kimia UNP Padang dan telah terjadinya silt yang mendesak permukaan. Sruktur batuan pada Kampus UNP sebelah Timur struktur batuannnya masih selaras. Adanya penyusupan Sandstone ke dalam Silt, kondisi ini dipertimbangkan untuk membuat struktur bangunan ke depan.

\section{DAFTAR PUSTAKA}

[1]. Harvey, P.K., Brewer, T.S., Pezard, P.A., and Petrov, V.A. Perophysical Properties of Crystalline Rocks. Geological Society, London. Special Publication. 240. 95-106., 2005

[2]. Samodra, H. (2008). Geologi Batuan Dasar Gunung Ciremai Jawa Barat. Jurnal Geologi Indonesia 4(5). Hlm. 279-287

[3]. Maiti,S. G. Gupta, , V. C. Erram, and R. K. Tiwari, Inversion of Schlumberger resistivity sounding data from the critically dynamic Koyna region using the Hybrid Monte Carlo-based neural network approach Indian Institute of Geomagnetism (DST), Navi Mumbai410218, India National Geophysical Research Institute (CSIR).

[4]. Loke, H.M, Res2Dinv Rapid 2D Resistivity \& IP Inversion, for Windows $X P /$ Vista, Goetoma Software Malaysia, 2009

[5]. Abdul-Nafiu, A.K, Nawawi, M. M. N., Khiruddin, A, Ishola, K. S and Abdulrahman, A, Effects Of Electrode Spacing And Inversion Techniques On The Efficacy of $2 d$ Resistivity Imaging To Delineate Subsurface Features, American Journal of Applied Sciences, 10 (1): 64-72, 2013

[6]. Chambers, J.E., P.B. Wilkinson, D.A. Gunn, R.D. Ogilvy, G.S. Ghataora, M.P.N. Burow, Tilden, S.R, Noninvasive characterization and monitoring of earth embankments using Electrical Resistivity Tomography 
$(E R T)$., British Geological Survey, UK, 2007.

[7]. Aihzegbobor, Philips Aizebeokhai, 2D and $3 D$ geoelectrical resistivity imaging: Theory and field design, Academic American Journals Department of Physics, Covenant University, Ota, Ogun State, Nigeria. 2010.

[8]. Telford, W.M., Geldart, L.P., and Sheriff, R.E. (1990). Applied Geophysics. New York: Cambridge University Press.

[9]. Akmam. Existensi of Spring in Batulimbak Village Simawang Kecamatan Rambatan Kabupaten Tanahdatar. Jurnal Prosiding Seminar PPD Forum HEDS 2004 Bidang MIPA, ISBN 979-95726-7-3. Hlm 593-608. 2004

[10]. Constable, S.C, Robert L. Parker, and Catherine G. Constable, Occam's Inversion: A Practical Algorithm For Generatlng Smooth Models From Electromagnetic Sounding Data, Jurnal Geophysics, vol. 52, no. 3 , 1987: page 289-300,

[11]. Gupta, S.K, Sri Niwas and Vinod K. Gaur, Straightforward inversion of vertical electrical sounding data, Jurnal Geophysics, vol. 62, no. 3, 1997); page. 775-785

[12]. Møller, I, Bo H. Jacobsen, and Niels

B. Christensen, Rapid inversion of 2-D geoelectrical data by multichannel deconvolution, Geophysics, vol. 66, no. 3 ; p. $800-808$,

[13]. Akmam, Doddy Sutarno, Pemodelan Inversi Satu Dimensi Data
Magnetotellurik Memodifikasi Inversi Occam dengan Pemotongan Nilai Singuler, Jurnal Kontribusi Fisika Indonesia, Vol. 8 No. 21997.

[14]. Degroot-Hedlin, Catherine and Steven Constable, Occam's Inversion and the North American Central Plains Electrical Anomaly, Institute of Geophysics and Planetary Physics, La Jolla, CA92093-0225, U.S.A. 1990

[15]. Degroot-Hedlin, C and S. Constable, Occam's Inversion to Generate Smooth,Two-Dimensional Models from Magnetotelluric data, Jurnal Geophysics, vol. 55, no. 12 page 16131624,1990

[16]. Supriyanto. (2007). Analisis Data Geofisika: Memahami Teori Inversi (Edisi I). Departemen Fisika-FMIPA Universitas Indonesia 2007.

[17]. Reynolds, J.M. An Introduction to Applied and Environmental Geophysics. New York: John Willey and Sons. 1997

[18]. Zhang Luo-Lei, Yu Peng, Wang JiaLin, Wu Jian-Sheng, Smoothest Model And Sharp Boundary Based TwoDimensional Magnetotelluric Inversion, Smoothest Model And Sharp Boundary Based Two-Dimensional Magnetotelluric Inversion, Chinese Journal Of Geophysics Vol.52, No.6, Page: 1360-1368, 2009

[19]. Gyulai, A, Tamás Ormos, Mihály Dobroka, A Quick 2-D Geoelectric Inversion Method Using Series Expansion, Journal of Applied Geophysics, ww.elsevier.com/ locate/jap 